\title{
"Porcine Digestible Peptides (Pdp) in Weanling Diets Improves Gut Barrier Function, Immune Response and Nutrient Transport in Nursery Pigs"
}

\section{Francesc González-Solé}

Universitat Autonoma de Barcelona

Lourdes Criado-Mesas

CRAG

\section{Carmen Villodre}

Universitat Autonoma de Barcelona

Wellington C. García

Universitat Autonoma de Barcelona

\section{Mercè Farré}

Universitat Autonoma de Barcelona

\section{Elisabet Borda}

Bioiberica SA

Francisco J. Pérez-Cano

Universitat de Barcelona

Josep M. Folch

Universitat Autonoma de Barcelona

David Solà-Oriol ( $\square$ david.sola@uab.cat)

Universitat Autonoma de Barcelona https://orcid.org/0000-0001-8365-340X José F. Pérez

Universitat Autonoma de Barcelona

\section{Research}

Keywords: bioactive peptides, gene expression, high throughput RT-qPCR, intestinal function, piglet, porcine digestible peptides

Posted Date: June 24th, 2020

DOI: https://doi.org/10.21203/rs.3.rs-36617/v1

License: (c) (1) This work is licensed under a Creative Commons Attribution 4.0 International License. Read Full License 


\section{Abstract}

Background: Porcine digestive peptides (PDP) have proven to be a valid substitute for other high-quality dietary protein sources for piglets, like spray-dried plasma (SDP), but knowledge about their influence on intestinal function is still scarce. This study was conducted to investigate the effects of PDP, SDP or a combination of both on growth performance and intestinal function of weaned pigs.

Results: A total of 180 piglets (Trial 1) and 198 piglets (Trial 2) were used to evaluate the partial substitution of soybean ingredients with $2 \%$ SDP or $2 \%$ PDP (Trial 1 ), and with $3 \%$ SDP or the combination of $1 \%$ SDP and $2 \%$ PDP (SDP-PDP; Trial 2) during the pre-starter period (d0-14). A common commercial diet was offered up to day 35 in Trial 2. The effects on intestinal function were evaluated by quantifyingthe gene expression (56 genes in an Open Array Real-Time PCRPlatform) in jejunum and ileum samples obtained from piglets on d 14 after weaning (Trial 2). Piglets fed SDP, PDP and SDP-PDP had a higher body weight (BW), average daily gain (ADG) and feed efficiency (G:F) than the soybean controlon day $14(P<0.05)$, but no differences were observed among groups at the end of starter phase (Trial 2). Ten genes in jejunum and five in ileum samples were differentially expressed among treatments $(P<0.05)$. The highest expression was found in the SDP-PDP group. These genes are involved in the barrier function of intestinal cells,the immune response, mucosal nutrient transport, digestion and metabolization of oxidation products.

Conclusion: The combination of SDP and PDP upregulated genes related to the intestinal functionwithout affecting growth performance. The underlying mechanisms that produced these effects are still unknown; however, protein hydrolysates might contain bioactive peptides that could be the cause.

\section{Background}

Weaning is a stressful period for piglets as they have to deal with a change from sow milk to a less digestible, plant-based dry solid diet that contains many ingredients that the pig has not eaten before [1]. The first consequence of weaning is a reduction in feed intake, which in turn causes a reduction in the villi height [2] and a disruption of the gut microbiota ecosystem with a loss of diversity [3]. After weaning, piglets are more susceptible to gut inflammatory problems and their intestinal function can be affected. This often leads to post-weaning diarrhea and increased mucosal permeability [4]. A strategy for helping piglets to reduce intestinal disturbances during this period is to include high-quality digestible animal protein sources in their feed. Certain protein sources, like spray-dried plasma (SDP) contain biologically active components that give them physiological or regulatory functions beyond their nutritional value [5]. In particular, SDP has shown potential for modulating the immune response, reducing intestinal mucosa inflammation and maintaining its integrity [6-8].

Porcine digestible peptides (PDP) are a coproduct of the heparin industry and are obtained from the enzymatic hydrolysis of porcine intestinal mucosa. Currently, PDP can be used in postweaning diets as a substitute for SDP, fish meal and other sources of high-quality protein in terms of preference and digestibility $[9,10]$. The ability of PDP to increase villous height suggests that they may improve gut health 
and nutrient uptake [11]. Like other sources of protein hydrolysates, PDP may also have implications for intestinal physiology as specific bioactive peptides have a key biological function in the barrier and immune function, and nutrient transport in the small intestine [5,12]. However, there is no available literature exploring possible functional properties of PDP. In the present study, in a first trial we hypothesize that including PDP and SDP in a high crude protein (CP) diet containing a high content of soybean ingredients might improve piglet performance after weaning (Trial 1). In a second trial we also hypothesize that partially substituting soybean meal (SBM) in weanling diets with SDP or a combination of SDP and PDP could improve piglet performance and intestinal function during the pre-starter period (Trial 2). Intestinal function was evaluated using the Open Array technology. The selected genes based on a literature review were representative target genes from different functional groups.

\section{Methods}

\section{Animals, Housing and Diet}

Trial 1. The first trial was conducted in the weanling unit of a commercial farm throughout the pre-starter period (d 0 to 14 post-weaning).

A total of 180 male and female weaned commercial crossing piglets ([Landrace $x$ Large White] $x$ Pietrain, weaned at d 28) with a body weight (BW) of $7.5 \pm 1.15 \mathrm{~kg}$ without previous access to creep feed during lactation were moved to the nursery unit. Piglets were distributed into two blocks according to initial BW (heavy piglets: $8.6 \pm 0.03 \mathrm{~kg}$; light piglets: $6.4 \pm 0.02 \mathrm{~kg}$ ). Each block contained 9 pens of 10 animals to which the three experimental treatments were randomly assigned ( 6 pens or replicates/treatment). Each pen (3.2 $\mathrm{m}^{2}$ in floor area) had a commercial non-lidded hopper (TR5, Rotecna, Agramunt, Spain) and a nipple waterer to ensure ad libitum feeding and free water access.

Treatments consisted of three different iso-protein pre-starter diets: a control diet (CON) with a high content of soybean ingredients and two extra diets with partial replacement of the extruded soybeans by 2\% SDP (AP 820 P, APC Europe S.L., Granollers, Spain) or 2\% PDP (Palbio 62SP, Bioiberica S.A.U., Palafolls, Spain). The basal pre-starter diet was formulated to contain 2,470 kcal of net energy (NE)/kg, $19.5 \% \mathrm{CP} / \mathrm{kg}$ and $1.28 \%$ dig Lys (Table 1 ) to meet the requirements for maintenance and growth of newly weaned piglets [13]. Diets were presented in mash form and were fed ad libitum for fourteen consecutive days. No antimicrobials or $\mathrm{ZnO}$ were used in the experimental diets. 
Table 1

Composition of the experimental diets used ontrial $1, \%$ as feed basis.

\begin{tabular}{|c|c|c|c|}
\hline \multirow[b]{2}{*}{ Item } & \multicolumn{3}{|c|}{ Experimental diets ${ }^{1}$} \\
\hline & $\mathrm{CON}$ & SDP & PDP \\
\hline \multicolumn{4}{|l|}{ Ingredient, \% } \\
\hline Maize & 36.9 & 38.7 & 38.8 \\
\hline Wheat & 16.0 & 16.0 & 16.0 \\
\hline ExtrudedSoybeans & 15.0 & 11.4 & 11.2 \\
\hline Barley & 13.0 & 13.0 & 13.0 \\
\hline Soybeanmeal 44\% CP & 6.8 & 6.8 & 6.8 \\
\hline Soybeanproteinconcentrate $56 \% \mathrm{CP}$ & 5.6 & 5.6 & 5.6 \\
\hline Sweet milkwhey & 2.5 & 2.5 & 2.5 \\
\hline Spray-dried plasma $80 \% \mathrm{CP}$ & - & 2.0 & - \\
\hline Porcine digestible peptides $62 \% \mathrm{CP}$ & - & - & 2.0 \\
\hline Mono calciumphosphate & 1.34 & 1.37 & 1.30 \\
\hline Calcium carbonate & 0.62 & 0.64 & 0.67 \\
\hline L-Lysine HCL & 0.55 & 0.49 & 0.52 \\
\hline Salt & 0.53 & 0.40 & 0.16 \\
\hline Vitamin-Mineral premix ${ }^{2}$ & 0.40 & 0.40 & 0.40 \\
\hline DL-Methionine & 0.27 & 0.23 & 0.57 \\
\hline L-Threonine & 0.25 & 0.21 & 0.23 \\
\hline L-Valine & 0.15 & 0.11 & 0.18 \\
\hline L-Tryptophan & 0.09 & 0.08 & 0.10 \\
\hline \multicolumn{4}{|l|}{ Calculatedcomposition } \\
\hline $\mathrm{NE}, \mathrm{kcal} / \mathrm{kg}$ & 2470 & 2470 & 2470 \\
\hline DryMatter, \% & 89.1 & 89.0 & 89.1 \\
\hline Ash, \% & 5.4 & 5.3 & 5.4 \\
\hline CrudeProtein, \% & 19.5 & 19.7 & 19.5 \\
\hline Calcium, \% & 0.650 & 0.655 & 0.650 \\
\hline
\end{tabular}




\begin{tabular}{|c|c|c|c|}
\hline Total P, \% & 0.678 & 0.671 & 0.671 \\
\hline \multicolumn{4}{|c|}{ Digestible amino acids } \\
\hline Lys, \% & 1.280 & 1.280 & 1.280 \\
\hline Met, \% & 0.509 & 0.470 & 0.829 \\
\hline Cys, \% & 0.222 & 0.262 & 0.213 \\
\hline Met+Cys, \% & 0.768 & 0.768 & 1.078 \\
\hline Thr, \% & 0.832 & 0.832 & 0.832 \\
\hline Trp, \% & 0.282 & 0.282 & 0.282 \\
\hline Val, \% & 0.896 & 0.896 & 0.934 \\
\hline \multicolumn{4}{|c|}{$\begin{array}{l}{ }^{1} \mathrm{CON} \text { : Control diet; SDP: Diet with } 2 \% \text { spray-dried plasma inclusion; PDP: Diet with } 2 \% \text { porcine } \\
\text { digestible peptides inclusion. }\end{array}$} \\
\hline \multicolumn{4}{|c|}{$\begin{array}{l}\text { 2Supplied the following per kg of diet: 7,000 IU of vitamin A (acetate); } 500 \text { IU of vitamin D3 } \\
\text { (cholecalciferol); } 250 \text { IU of vitamin D (25-hydroxicholecalciferol); } 45 \mathrm{mg} \text { of vitamin E; } 1 \mathrm{mg} \text { of vitamin } \\
\text { K3; } 1.5 \mathrm{mg} \text { of vitamin B1; } 3.5 \mathrm{mg} \text { of vitamin B2; } 1.75 \mathrm{mg} \text { of vitamin B6; } 0.03 \mathrm{mg} \text { of vitamin B12; } 8.5 \\
\mathrm{mg} \text { of D-pantothenic acid; } 22.5 \mathrm{mg} \text { of niacin; } 0.1 \mathrm{mg} \text { of biotin; } 0.75 \mathrm{mg} \text { of folacin; } 20 \mathrm{mg} \text { of Fe (chelate } \\
\text { of amino acids); } 2.5 \mathrm{mg} \text { of Cu (sulphate); } 7.5 \mathrm{mg} \text { of Cu (chelate of glycine); } 0.05 \mathrm{mg} \text { of Co (sulphate); } \\
40 \mathrm{mg} \text { of } \mathrm{Zn} \mathrm{(oxide);} 12.5 \mathrm{mg} \text { Zn (chelate of amino acids); } 12.5 \mathrm{mg} \text { of Mn (oxide); } 7.5 \mathrm{of} \text { Mn (chelate } \\
\text { of glycine); } 0.35 \mathrm{mg} \text { of I, } 0.5 \text { of Se (organic); } 0.1 \mathrm{mg} \text { of Se (sodium). }\end{array}$} \\
\hline
\end{tabular}

Trial 2. The second trial was conducted in a different commercial farm throughout the pre-starter ( $\mathrm{d} 0$ to 14 post-weaning) and starter period (d 14 to 35 post-weaning).

A total of 198 male and female weaned commercial crossing piglets ([Landrace $x$ Large White] $x$ Pietrain, weaned at $\mathrm{d} 21$ ) with a BW of $5.7 \pm 0.60 \mathrm{~kg}$ that had access to creep feed during lactation, were moved to the nursery unit without transport to be used in the trial.

Animals were distributed into two blocks according to initial BW (heavy piglets: $6.3 \pm 0.02 \mathrm{~kg}$; light piglets: $5.1 \pm 0.01 \mathrm{~kg}$ ) and each block contained 9 pens of 11 animals to which three experimental treatments were randomly assigned (6 replicates for each treatment). Each pen ( $3 \mathrm{~m}^{2}$ in floor area) had a commercial non-lidded hopper (TR5, Rotecna) and a nipple waterer to ensure ad libitum feeding and free water access.

Treatments consisted of three different iso-protein pre-starter diets: a CON diet with a high content of SBM and two extra diets with partial replacement of the SBM by $3 \%$ Spray-dried Plasma (SDP; AP 820 P, APC Europe S.L.) or a combination of $1 \%$ Spray-dried Plasma and $2 \%$ Porcine Digestible Peptides (SDPPDP; Palbio 62SP, Bioiberica S.A.U.). 
The basal pre-starter diet was formulated to contain 2,470 kcal NE/kg, 20.5\% CP/kg and $1.35 \%$ dig Lys (Table 2) and to meet the requirements for maintenance and growth of newly weaned piglets [14]. The pre-starter diets were fed ad libitum for fourteen consecutive days and a common starter diet was also fed ad libitum from d 15 until d 35 post-weaning (Table 2). No antibiotics, alternative antimicrobials or $\mathrm{ZnO}$ were included in the diets. 
Table 2.

Composition of the experimental diets used on trial 2 (\%, as feed basis).

\begin{tabular}{|c|c|c|c|c|}
\hline \multirow[b]{2}{*}{ Item } & \multicolumn{4}{|c|}{ Experimental diets ${ }^{1}$} \\
\hline & CON & SDP & SDP-PDP & Starter \\
\hline \multicolumn{5}{|l|}{ Ingredients, \% } \\
\hline Corn & 29.68 & 32.53 & 32.11 & - \\
\hline Maize & - & - & - & 29.79 \\
\hline SoybeanMeal 47\% CP & 25.82 & 20.6 & 21.34 & 21.34 \\
\hline Wheat & 16 & 16 & 16 & 15 \\
\hline Barley & 6.5 & 6.5 & 6.5 & 20 \\
\hline Dextrose & 6.5 & 6.5 & 6.5 & - \\
\hline Sweet MilkWhey & 6.5 & 6.5 & 6.5 & - \\
\hline Potato Protein & 2.5 & 2.5 & 2.5 & - \\
\hline Lard & 2.67 & 2.38 & 2.31 & 6.53 \\
\hline Di-calciumphosphate & 1.72 & 1.77 & 1.67 & 1.56 \\
\hline Spray-dried plasma (80\% CP) & - & 3 & 1 & - \\
\hline Porcine digestible peptides $62 \% \mathrm{~PB}$ & - & - & 2 & - \\
\hline Salt & 0.47 & 0.27 & 0.03 & 0.48 \\
\hline Vitamin-Mineral Premix ${ }^{2}$ & 0.4 & 0.4 & 0.4 & 0.40 \\
\hline L-Lysine HCL (78) & 0.46 & 0.39 & 0.39 & 0.51 \\
\hline DL-Methionine & 0.27 & 0.24 & 0.25 & 0.25 \\
\hline L-Threonine & 0.21 & 0.16 & 0.17 & 0.24 \\
\hline Calcium Carbonate & 0.11 & 0.11 & 0.17 & 0.55 \\
\hline L-Valine & 0.11 & 0.09 & 0.08 & 0.14 \\
\hline L-Tryptophan & 0.08 & 0.07 & 0.09 & 0.07 \\
\hline \multicolumn{5}{|l|}{ Calculatedcomposition } \\
\hline $\mathrm{NE}, \mathrm{kcal} / \mathrm{kg}$ & 2470 & 2470 & 2470 & 2653 \\
\hline EtherExtract, \% & 4.69 & 4.43 & 4.39 & 8.61 \\
\hline Neutral DetergentFibre, \% & 7.87 & 7.57 & 7.61 & 9.92 \\
\hline
\end{tabular}




\begin{tabular}{|lllll}
\hline CrudeProtein, \% & 20.51 & 20.50 & 20.50 & 18.50 \\
\hline Calcium, \% & 0.65 & 0.65 & 0.65 & 0.73 \\
\hline Total P, \% & 0.70 & 0.68 & 0.68 & 0.65 \\
\hline Digestible amino acids & & & & \\
\hline Lys, \% & 1.350 & 1.350 & 1.350 & 1.230 \\
\hline Met, \% & 0.545 & 0.504 & 0.539 & 0.478 \\
\hline Met+Cys, \% & 0.810 & 0.810 & 0.810 & 0.720 \\
\hline Thr, \% & 0.878 & 0.878 & 0.878 & 0.780 \\
\hline Trp, \% & 0.297 & 0.297 & 0.297 & 0.264 \\
\hline Analyzedcomposition & & & & 89.3 \\
\hline DryMatter,\% & 90.3 & 92.3 & 91.8 & 8.4 \\
\hline EtherExtract, \% & 4.6 & 4.3 & 4.1 & - \\
\hline Neutral DetergentFibre, \% & 9.7 & 7.7 & 8.2 & 17.7 \\
\hline CrudeProtein, \% & 19.7 & 18.7 & 19.6 & \\
\hline
\end{tabular}

${ }^{1} \mathrm{CON}$ : Control diet; SDP: Diet with $3 \%$ spray-dried plasma inclusion; SDP-PDP: Diet supplemented with a combination of $1 \%$ spray-dried plasma and $2 \%$ porcine digestible peptides.

${ }^{2}$ Supplied the following per kg of diet: 7,000 IU of vitamin A (acetate); 500 IU of vitamin D3 (cholecalciferol); 250 IU of vitamin D (25-hydroxicholecalciferol); $45 \mathrm{mg}$ of vitamin E; $1 \mathrm{mg}$ of vitamin $\mathrm{K} 3 ; 1.5 \mathrm{mg}$ of vitamin B1; $3.5 \mathrm{mg}$ of vitamin B2; $1.75 \mathrm{mg}$ of vitamin $\mathrm{B} 6 ; 0.03 \mathrm{mg}$ of vitamin $\mathrm{B} 12 ; 8.5$ $\mathrm{mg}$ of D-pantothenic acid; $22.5 \mathrm{mg}$ of niacin; $0.1 \mathrm{mg}$ of biotin; $0.75 \mathrm{mg}$ of folacin; $20 \mathrm{mg}$ of Fe (chelate of amino acids); $2.5 \mathrm{mg}$ of $\mathrm{Cu}$ (sulphate); $7.5 \mathrm{mg}$ of $\mathrm{Cu}$ (chelate of glycine); $0.05 \mathrm{mg}$ of Co (sulphate); $40 \mathrm{mg}$ of $\mathrm{Zn}$ (oxide); $12.5 \mathrm{mg} \mathrm{Zn}$ (chelate of amino acids); $12.5 \mathrm{mg}$ of Mn (oxide); 7.5 of Mn (chelate of glycine); $0.35 \mathrm{mg}$ of I, 0.5 of Se (organic); $0.1 \mathrm{mg}$ of Se (sodium).

\section{Data and Sample Collection}

Piglets were ear tagged and individually weighed at weaning ( $(\mathrm{d} 0)$ and $\mathrm{d} 14$ post weaning in trial 1 and at weaning ( $d 0), d 7, d 14$ and $d 35$ post-weaning in trial 2 . Feed disappearance from each hopper was measured throughout the experimental period. The average daily feed intake (ADFI), average daily gain $(A D G)$ and feed efficiency (G:F) were calculated for the experimental period.

One piglet per pen was euthanized on d 14 in trial 2. A portion of $0.5 \mathrm{~cm}$ of jejunum and ileum tissues were collected at $30 \mathrm{~cm}$ and $1.3 \mathrm{~cm}$ from the ileo-cecal valve respectively and immediately snap frozen in $1 \mathrm{~mL}$ of RNA later (Deltalab, Rubí, Spain). Samples were stored at $-80^{\circ} \mathrm{C}$ until use.

\section{Analysis}

Diet proximate analyses from trial 2 were performed following the Association of Official Agricultural Chemists methodology: dry matter (AOAC 934.01 [15]), ash (AOAC 942.05 [16]), ether extract (AOAC 
2003.05 [16]) and crude protein (AOAC 968.06 [17]). Neutral-detergent fiber was determined according to the method of Van Soest et al. [18].

\section{Gene Expression Study by qPCR}

Gene expression was quantified by RT-qPCR to study the expression of 56 genes in two intestinal tissues in an Open Array Real-Time PCR Platform (Applied Biosystems, Waltham, MA, USA) by the Servei Veterinari de Genètica Molecular at the Veterinary Faculty of the Universitat Autònoma de Barcelona (Spain).

The pre-amplified product was diluted 1:10 with $0.1 \mathrm{X}$ Tris-EDTA pH 8.0 and 6 ul was transferred to 384well plates. These were analyzed in duplicate in Taqman Open Array gene expression plates customdesigned in a QuantStudio 12K Flex Real-Time PCR system (ThermoFisher Scientific, Waltham, MA, USA). One sample was used as an inter-plate control to check the replication of results from different plates.

\section{Open Array Design}

A list of 56 genes related to intestinal health were selected according to the bibliography [19-32] and included: (1) genes participating in the barrier function (OCLN, ZO1, CLDN1, CLDN4, CLDN15, MUC2, MUC13 and TFF3); (2) genes that play an important role in the immune response, such as pattern recognition receptors, cytokines, chemokines and stress proteins (TLR2, TLR4, IL 1B, IL6, IL8, IL 10, IL 17A, IL22, IFNG, TNF, TGFB1, CCL20, CXCL2, IFNGR1, HSPB1, HSPA4, REG3G, PPARGC1A, FAXDC2 and GBP1); (3) genes coding for enzymes and hormones implicated in the digestion process (GPX2, SOD2, ALPI, SI, DAO1, HNMT, APN, IDO1, GCG, CCK, IGF1R and PYY); (4) genes involved in nutrient transport (SLC5A1, SLC16A1, SLC7A8, SLC15A1, SLC13A1, SLC11A2, MT1A, SLC30A1 and SLC39A4); (5) and genes involved in the stress response (CRHR1, NR3C1 and HSD11B1); and (6) four reference genes ( $A C T B, B 2 M, G A P D H$ and $T B P)$.

Primers were designed spanning exon-exon boundaries or at different exons using the PrimerExpress 2.0 software (Applied Biosystems) for 55 genes. The $I L 8$ gene primer was pre-designed by the company due to its complexity (see Additional file). Possible residual genomic DNA amplification and primer dimer formation were controlled. Finally, a customized Open Array panel containing 56 genes was obtained.

\section{RNA Extraction and cDNA Preparation}

Total RNA was obtained from $100 \mathrm{mg}$ of frozen intestinal tissues with the RiboPure kit (Ambion, Austin, TX, USA) following the manufacturer's protocol. RNA concentration and purity was calculated with a NanoDrop ND-1000 spectrophotometer (NanoDrop products, Wilmington, DE, USA). RNA integrity was checked with Agilent Bioanalyzer-2100 equipment (Agilent Technologies, Santa Clara, CA, USA) following the producer's protocol. One microgram of total RNA was reverse-transcribed into CDNA in a final volume of $20 \mu \mathrm{l}$. The High-Capacity cDNA Reverse Transcription kit (Applied Biosystems) and random hexamer primers were used, and the following thermal profile was applied: $25^{\circ} \mathrm{C}, 10 \mathrm{~min} ; 37^{\circ} \mathrm{C}, 120 \mathrm{~min} ; 85^{\circ} \mathrm{C}, 5$ sec; $4^{\circ} \mathrm{C}$ hold. A total of $25 \mathrm{ng}$ of cDNA sample was pre-amplified using a $2 X$ TaqMan ${ }^{\circledR}$ PreAmp Master Mix and a 0.2X Pooled Taqman Gene Expression custom Assays in a final volume of $10 \mu \mathrm{l}$. The thermal 
cycling conditions for the pre-amplification reactions were $10 \mathrm{~min}$ at $95^{\circ} \mathrm{C} ; 14$ cycles of $15 \mathrm{sec}$ at $95^{\circ} \mathrm{C}$ and $4 \mathrm{~min}$ at $60^{\circ} \mathrm{C}$; and a final step of $10 \mathrm{~min}$ at $99^{\circ} \mathrm{C}$. The pre-amplified cDNA product was stored at -20 ${ }^{\circ} \mathrm{C}$ until use.

\section{Gene Expression Data Analysis}

Gene expression data were collected and analyzed using the ThermoFisher Cloud software 1.0 (Applied Biosystems) applying the $2^{-\Delta \Delta C t}$ method for relative quantification (RQ) and using the sample with the lowest expression as a calibrator. Some parameters were adjusted: the maximum cycle relative threshold (Crt) allowed was 26, amplification score $<1.240$, quantification cycle confidence $>0.8$, and the maximum standard deviation allowed between duplicates was set at $<0.38$. Samples that did not fit these requirements or had an inconclusive amplification status were deleted. RQ values were checked for normalization by $\log _{10}$ transform, and all the statistical analyses were performed with the R 3.4.3 software [33] and Bioconductor [34]. We carried out a one-way ANOVA and calculated the BenjaminiHochberg false discovery rate (FDR $Q$-value) to control multiple $P$-values [35], setting an upper bound for the expected proportion of false significant tests, that is, false significant treatment differences in mean expression levels between treatments. Pairwise post hoc treatment comparisons were carried out using Tukey's honest significant difference test [36]. Statistical differences between results for the treatments were identified at $P$-values under 0.05 for the ANOVA and Tukey's analysis, and $Q$-values under 0.2 for the FDR.

A principal component analysis (PCA) was performed with samples as cases and gene $\log _{10}$-expressions as variables. The function PCA of the FactoMiner R-library [37] was used for dimension reduction and visualization in the first two principal dimensions. The variables factor map was restricted to genes showing cos2-qualities over 0.45 and significant differences. This graph shows which of these genes are correlated along the samples. The sample identifier numbers are represented in the individual factor map, or factorial scores map, and are colored according to the diet assigned to each sample. Finally, the heatmap visualization method was used to obtain double clustering both for genes (with a correlationbased distance: $d=(1-r) / 2$, in which $\mathrm{d}$ is distance and $\mathrm{r}$ is the correlation coefficient, and the complete linkage hierarchical clustering) and for samples (with Euclidean distance and Ward's D2 method). These methods were chosen based on the following: the Euclidian distance between two samples adds all the squared differences in the log-expression level of them in each gene, and then the Ward's D2 linkage method uses the Euclidean squared-distance to cluster in a way that minimizes the increment of the variance into the resulting clusters. Correlation based distance is preferred for obtaining the gene clusters because the expression levels in different genes may not be comparable (see Murtagh and Legendre [38], for Ward's method and Everitt [39], for clustering methods). The function heatmap.2 in the R-library gplots was used [40].

\section{Statistical Analysis}

Production performance data were analyzed with ANOVA using the generalized linear model procedure of the statistical package SASß (version 9.4, SAS Inst.Inc., Cary, NC). Normality and homoscedasticity were 
checked with Shapiro-wilk's test using the Univariate procedure and Levene's test using the generalized linear model procedure respectively. Data were analyzed taking the experimental treatment and the block of weight as the main factors. Their corresponding interaction was also included in the model. The statistical unit was the pen of 10 pigs in trial 1 and the pen of 11 pigs in trial 2 . The results are presented as least square means taking into account the Tukey adjust. The level of significance considered was $a=$ 0.05 .

\section{Results}

\section{Growth Performance}

The productive performance of piglets during the first two weeks after weaning (Trial 1) is summarized in Table 3. Animals fed SDP and PDP showed higher BW, ADG and G:F $(P<0.05)$ than piglets in the control group.

Table 3

Effect of the experimental treatments on growth performance of piglets in trial 1.

\begin{tabular}{|c|c|c|c|c|c|}
\hline \multicolumn{6}{|c|}{ Experimental diets ${ }^{1}$} \\
\hline Item & CON & SDP & PDP & SEM & $P$-value \\
\hline BW, day $0, \mathrm{~g}$ & 7505 & 7517 & 7534 & 12.0 & 0.241 \\
\hline day $14, \mathrm{~g}$ & $9438^{b}$ & $10381^{a}$ & $9990^{a}$ & 138.9 & 0.001 \\
\hline ADFI 0-14d, g/d & $236^{\mathrm{b}}$ & $295^{\mathrm{a}}$ & $250^{b}$ & 11.3 & 0.002 \\
\hline ADG 0-14d, g/d & $138^{\mathrm{b}}$ & $205^{\mathrm{a}}$ & $175^{\mathrm{a}}$ & 11.8 & 0.002 \\
\hline G:F 0-14d & $0.55^{\mathrm{b}}$ & $0.69^{a}$ & $0.70^{\mathrm{a}}$ & 0.041 & 0.034 \\
\hline \multicolumn{6}{|c|}{$P$-values come from the ANOVA test. } \\
\hline \multicolumn{6}{|c|}{${ }^{1}$ BW: body weight; ADFI: average daily feed intake; ADG: average daily gain; G:F: feed efficiency. } \\
\hline \multicolumn{6}{|c|}{$\begin{array}{l}{ }^{2} \mathrm{CON} \text { : Control diet; SDP: Diet with } 3 \% \text { spray-dried plasma inclusion; SDP-PDP: Diet supplemented witl } \\
\text { a combination of } 1 \% \text { spray-dried plasma and } 2 \% \text { porcine digestible peptides. }\end{array}$} \\
\hline
\end{tabular}

For trial 2, the productive performance results are shown in Table 4. Piglets of the SDP and SDP-PDP group showed greater BW and ADG and G:F than CON piglets on $\mathrm{d} 14(P<0.05)$. Although a numeric difference in BW was observed at $d 35$ between the supplemented animals and the CON group, no significant differences in BW, ADG or G:F were observed. 
Table 4

Effect of the experimental treatments on growth performance of piglets in trial 2.

\begin{tabular}{|c|c|c|c|c|c|}
\hline \multicolumn{6}{|c|}{ Experimental diets ${ }^{2}$} \\
\hline Items $^{1}$ & CON & SDP & SDP-PDP & SEM & $P$-value \\
\hline BW, day $0, \mathrm{~g}$ & 5724 & 5720 & 5721 & 46.9 & 0.859 \\
\hline day $7, g$ & $5956^{\mathrm{b}}$ & $6344^{\mathrm{a}}$ & $6254^{\mathrm{ab}}$ & 88.3 & 0.023 \\
\hline day $14, \mathrm{~g}$ & $7165^{\mathrm{b}}$ & $7894^{\mathrm{a}}$ & $7871^{a}$ & 152.7 & 0.008 \\
\hline day $35, \mathrm{~g}$ & 15270 & 16252 & 15960 & 460.3 & 0.335 \\
\hline ADFI, day $0-14, \mathrm{~g}$ & 267.4 & 282.9 & 283.3 & 5.96 & 0.139 \\
\hline day $14-35, \mathrm{~g}$ & 483.7 & 508.8 & 525.8 & 25.94 & 0.532 \\
\hline ADG, day $0-14, \mathrm{~g}$ & $103.1^{\mathrm{b}}$ & $155.3^{\mathrm{a}}$ & $153.6^{\mathrm{a}}$ & 10.68 & 0.007 \\
\hline day $14-35, \mathrm{~g}$ & 364.4 & 398.0 & 382.4 & 22.01 & 0.571 \\
\hline G:F, day $0-14$ & $0.38^{\mathrm{b}}$ & $0.55^{\mathrm{a}}$ & $0.54^{\mathrm{a}}$ & 0.038 & 0.046 \\
\hline day $14-35$ & 0.76 & 0.80 & 0.73 & 0.050 & 0.840 \\
\hline \multicolumn{6}{|c|}{$P$-values come from the ANOVA test. } \\
\hline \multicolumn{6}{|c|}{${ }^{1} \mathrm{BW}$ : body weight; ADFI: average daily feed intake; ADG: average daily gain; G:F: feed efficiency. } \\
\hline \multicolumn{6}{|c|}{$\begin{array}{l}{ }^{2} \mathrm{CON} \text { : Control diet; SDP: Diet with } 3 \% \text { spray-dried plasma inclusion; SDP-PDP: Diet supplemented wit } \\
\text { a combination of } 1 \% \text { spray-dried plasma and } 2 \% \text { porcine digestible peptides. }\end{array}$} \\
\hline $\begin{array}{l}\text { a,b Different letters } \\
\text { (Tukey's test } P \text {-valt }\end{array}$ & row inc & ignifica & stical me & nces & wo diets \\
\hline
\end{tabular}

\section{Intestinal Mucosa Gene Expression Values}

After performing qPCR of the intestinal tissue, 37 genes were detected as expressed in jejunum tissue and 27 genes in ileum tissue from the 54 target genes initially included in the Open Array panel. The conservation of one tissue sample from the jejunum and seven from the ileum was affected and amplification was not possible.

The results of the analysis of gene expression in the jejunum intestinal tissue (Trial 2) are shown in Table 5. Ten genes showed differences between groups $(P<0.05, Q<0.2)$. In fact, all the $Q$-values in Table 6 are below 0.169 , which is the upper bound of the false positive proportion. The CLDN15 and TFF3 genes from the barrier function group and the SLC11A2/DMT1 gene from the nutrient transport group showed a higher expression for the SDP-PDP treatment compared to the CON treatment. From the immune response functional group, the SDP-PDP group showed a higher expression level in three genes: 
GBP1 compared to the SDP group, IFNGR1 compared to the CON group, and TLR4 compared to the other two groups. Finally, the SDP-PDP group had a higher expression level than the CON and SDP groups in two enzyme-coding genes ( $H N M T$ and $A P N)$, and in the gene coding for a protein that metabolizes oxidation products, SOD2.

Table 5

Effect of the experimental treatments on relative gene expression on jejunum mucosa after pre-starter period.

\begin{tabular}{|c|c|c|c|c|c|c|c|}
\hline \multirow[t]{2}{*}{ Function } & \multirow[t]{2}{*}{ Genes $^{1}$} & \multicolumn{3}{|c|}{ Experimental diets ${ }^{2}$} & \multirow{2}{*}{$\begin{array}{l}\text { Contrast } \\
\text { Statistic }\end{array}$} & \multirow{2}{*}{$\begin{array}{l}P \text {. } \\
\text { value }\end{array}$} & \multirow{2}{*}{$\begin{array}{l}\text { Q-value } \\
\text { (FDR) }\end{array}$} \\
\hline & & CON & SDP & $\begin{array}{l}\text { SDP- } \\
\text { PDP }\end{array}$ & & & \\
\hline \multirow{2}{*}{$\begin{array}{l}\text { Barrier } \\
\text { function }\end{array}$} & CLDN15 & $0.51^{\mathrm{b}}$ & $0.81^{a b}$ & $1.05^{\mathrm{a}}$ & 4.984 & 0.027 & 0.139 \\
\hline & TFF3 & $1.15^{\mathrm{b}}$ & $1.07^{\mathrm{ab}}$ & $1.83^{\mathrm{a}}$ & 4.290 & 0.035 & 0.145 \\
\hline \multirow{3}{*}{$\begin{array}{l}\text { Immune } \\
\text { response }\end{array}$} & TLR4 & $1.54^{\mathrm{b}}$ & $1.31^{b}$ & $2.86^{a}$ & 8.052 & 0.005 & 0.059 \\
\hline & GBP1 & $2.40^{\mathrm{ab}}$ & $1.80^{\mathrm{b}}$ & $4.20^{\mathrm{a}}$ & 5.711 & 0.015 & 0.127 \\
\hline & IFNGR1 & $0.69^{b}$ & $0.74^{\mathrm{ab}}$ & $1.10^{\mathrm{a}}$ & 4.661 & 0.028 & 0.139 \\
\hline \multirow{2}{*}{$\begin{array}{l}\text { Nutrient } \\
\text { transport }\end{array}$} & SLC11A2/ & $0.37^{b}$ & $0.71^{\mathrm{ab}}$ & $1.24^{\mathrm{a}}$ & 3.862 & 0.046 & 0.169 \\
\hline & DMT1 & & & & & & \\
\hline \multirow[t]{2}{*}{$\begin{array}{l}\text { Enzyme/ } \\
\text { Hormone }\end{array}$} & HNMT & $0.86^{b}$ & $0.91^{b}$ & $1.56^{\mathrm{a}}$ & 14.111 & $\begin{array}{l}4 \times \\
10^{-4}\end{array}$ & 0.015 \\
\hline & APN & $1.59^{b}$ & $1.40^{\mathrm{b}}$ & $3.40^{\mathrm{a}}$ & 4.577 & 0.030 & 0.139 \\
\hline Oxidation & SOD2 & $1.04^{\mathrm{b}}$ & $0.95^{\mathrm{b}}$ & $1.71^{\mathrm{a}}$ & 11.030 & 0.001 & 0.022 \\
\hline
\end{tabular}

Gene expression values are presented as ratios of cycle relative threshold (Crt) value for each gene normalized to that of the reference sample. $P$-values come from the ANOVA test and FDR is the false discovery rate.

${ }^{1}$ CLDN15: Claudin 15; TFF3: Trefoil Factor 3; SLC11A2/DMT1: Solute carrier family 11 member 2/ divalent metal transporter 1 (DMT1); TLR4: Toll like receptor 4; GBP1: Guanylate binding protein; IFNGR1: Interferon gamma receptor 1; HNMT: Histamine N-Methyltransferase; APN: Alanyl Aminopeptidase; SOD2: Superoxide dismutase 2.

${ }^{2} \mathrm{CON}$ : Control diet; SDP: Diet with $3 \%$ spray-dried plasma inclusion; SDP-PDP: Diet supplemented with a combination of $1 \%$ spray-dried plasma and $2 \%$ porcine digestible peptides $(2 \%)$.

a,b Different letters in the same row indicate significant statistical mean differences in the two diets (Tukey's test $P$-value $<0.05$ ).

The results of the analysis of gene expression in the ileum are shown in Table 6. Five genes showed significant differences among treatment means according to the ANOVA results $(P<0.05)$ but not 
according to the FDR $(Q>0.2)$. Three of the genes that were included in the barrier function group coded for mucins (MUC2 and MUC13) and occludin (OCLM) and had a higher mean expression in the SDP-PDP group than the CON group. From the immune response group, the GBP1 gene showed a higher expression level in the SDP-PDP treatment than in the SDP treatment. The gene coding the hormone glucagon (GCG) had a greater expression in the SDP-PDP group than in the SDP and CON groups.

Table 6

Effect of the experimental treatments on relative gene expression on ileum mucosa after pre-starter period.

\begin{tabular}{|c|c|c|c|c|c|c|c|}
\hline \multirow[t]{2}{*}{ Function } & \multirow[t]{2}{*}{ Genes $^{1}$} & \multicolumn{3}{|c|}{ Experimental diets ${ }^{2}$} & \multirow{2}{*}{$\begin{array}{l}\text { Contrast } \\
\text { Statistic }\end{array}$} & \multirow{2}{*}{$\begin{array}{l}P \\
\text { value }\end{array}$} & \multirow{2}{*}{$\begin{array}{l}\text { Q-value } \\
\text { (FDR) }\end{array}$} \\
\hline & & CON & SDP & $\begin{array}{l}\text { SDP- } \\
\text { PDP }\end{array}$ & & & \\
\hline \multirow[t]{3}{*}{ Barrier Function } & MUC13 & $1.37^{b}$ & $2.16^{\mathrm{ab}}$ & $3.22^{\mathrm{a}}$ & 4.619 & 0.046 & 0.278 \\
\hline & MUC2 & $1.47^{\mathrm{b}}$ & $2.32^{\mathrm{ab}}$ & $5.29^{a}$ & 5.048 & 0.038 & 0.278 \\
\hline & OCLN & $1.05^{\mathrm{b}}$ & $1.28^{\mathrm{ab}}$ & $1.99^{a}$ & 9.647 & 0.019 & 0.278 \\
\hline $\begin{array}{l}\text { Immune } \\
\text { Response }\end{array}$ & GBP1 & $1.07^{\mathrm{ab}}$ & $0.73^{b}$ & $2.10^{\mathrm{a}}$ & 5.384 & 0.033 & 0.278 \\
\hline Hormone & GCG & $1.12^{b}$ & $1.35^{\mathrm{b}}$ & $3.27^{a}$ & 7.192 & 0.016 & 0.278 \\
\hline
\end{tabular}

Gene expression values are presented as ratios of cycle relative threshold (Crt) value for each gene normalized to that of the reference sample. $P$-values come from the ANOVA test and FDR is the false discovery rate.

${ }^{1}$ MUC13: Mucin 13; MUC 2: Mucin 2; OCLN: Occludin; GBP1: Guanylate binding protein; GCG: Glucagon.

${ }^{2} \mathrm{CON}$ : Control diet; SDP: Diet with $3 \%$ spray-dried plasma inclusion; SDP-PDP: Diet supplemented with a combination of $1 \%$ spray-dried plasma and $2 \%$ porcine digestible peptides.

a,b Different letters in the same row indicate significant statistical mean differences in the two diets (Tukey's test $P$-value $<0.05$ ).

A PCA was carried out to determine the correlation in the gene expression values among samples distributed in the three diet groups (Fig. 1). The 2D representation preserves $60 \%$ of the total variance (61.27\% in the jejunum and $59.36 \%$ in the ileum). The results for the jejunum show a correlation in the gene expression pattern. In this tissue, eight of the nine significant genes (APN, HNMT, SLC11A2, CLCN15, IFNGR1, TLR4, GBP1 and SOD2) are well represented in 2D (long arrows) and all of them fall in the first quadrant. Furthermore, the blue colored samples in the SDP-PDP group fall in the same quadrant or near to it, which indicates medium to high expression levels. A similar conclusion can be drawn from the PCA plots for the ileum tissue. Here, four out of the five significant genes (OCLN, MUC13, GCG and MUC) show long arrows on the right-hand side of axis one, together with three of the four samples in the SDP-PDP group. Therefore, these plots clearly show a relationship between the highest expression levels in these 
significant genes and the SDP-PDP diet group. The CON and SDP groups are mixed and do not show high expression values.

$\mathrm{CON}=$ control diet; SDP = diet with 3\% spray-dried plasma inclusion; SDP-PDP = diet supplemented with a combination of $1 \%$ spray-dried plasma and $2 \%$ porcine digestible peptides. For each tissue, the samples' picture is on the left, labeled with different colors depending on the treatment, and the gene expressions arrows diagram on the right. Only those genes that are statistically significant and have a long arrow have been depicted. Each arrow color indicates a different functional group. Trial 2.

A heatmap was also made in order to observe overall similarities among the gene expression profiles of the animals (Fig. 2). On the jejunum and ileum heatmaps, part of the samples from the PDP-SDP treatment are clustered together but genes do not show any evidence of an association by functional group. Heatmaps and PCAs are exploratory techniques that both indicate that samples in the PDP-SDP group tend to cluster separated from the other two groups; however, PCA is more specific for indicating more clearly which gene expressions determine this clustering. All the results agree with the ANOVA and Tukey's test, but these analyses deal with mean treatment values while heatmaps and PCA-plots reflect individual performance.

CON = control diet SDP = diet with $3 \%$ spray-dried plasma inclusion; SDP-PDP = diet supplemented with a combination of $1 \%$ spray-dried plasma and $2 \%$ porcine digestible peptides. Genes are organized in rows and samples in columns. Samples are labeled with different colors representing every treatment and genes depending on its functional group.

\section{Discussion}

The diets in the present study were formulated to contain a high inclusion of soybean ingredients. The $\beta$ sheet structures of raw legume proteins and the intermolecular $\beta$-sheet aggregates derived from heating are negatively correlated with feed digestibility values [41]. The $\beta$-sheet structures represent more than $30 \%$ of the secondary structure of soybean seeds, while they represent less than $10 \%$ in the ingredients of animal origin [42]. Consequently, the flow of protein into the distal parts of the GIT tends to be larger when more soybean ingredients are included, which promotes protein fermentation and selective growth of proteolytic bacteria [42]. Furthermore, soybeans contain anti-nutritional factors, such as antigens, trypsin inhibitors and lectins, which can produce digestive disorders and reduce nutrient availability $[43,44]$. The consequences of high inclusion of soybean ingredients, aggravated by the situation of post-weaning anorexia, can lead to intestinal disorders, such as post-weaning diarrhea $[2,45]$. This can negatively affect the animal growth performance. In addition, proteins of animal origin as well as animal protein hydrolysates have higher palatability than vegetal proteins $[10,46,47]$, which can translate into an increased feed intake after weaning. The results of these trials demonstrate that including high-quality animal proteins, such as spray-dried plasma (SDP) and porcine digestible peptides (PDP), promotes a positive effect on growth performance of weanling piglets, increasing $B W, A D G$ and $G: F$ at the end of the pre-starter phase (d14). 
Spray-dried plasma improved the productive performance in all these trials, evidencing that it is a clear positive control. The results reported herein are similar to other studies that showed that SDP improved performance, especially when piglets were challenged with experimental infection and did not contain in feed medication [48]. SDP is commonly used because it can stimulate feed intake due to its palatability [49], as observed in Trial 1. Its beneficial effects are explained by the preservation of blood immunoglobulins, growth factors, and bioactive peptides or compounds during the spray-drying process. These components can interact with the gut-associated lymphoid tissue [50], therefore preserving the small intestinal barrier function and reducing intestinal inflammation and damage [6].

Consumption of feed containing the hydrolysates, PDP or SDP-PDP, enhanced the productive performance of piglets compared to their corresponding control group, and these groups were equivalent to the SDP group. This result is in accordance with other authors who also obtained similar growth performance by feeding PDP and SDP in early-weaned piglets [51]. Some research data have shown improved growth performance, feed intake and efficiency of animals fed PDP compared to other highquality protein sources like fish meal [46]. Other studies indicate that PDP might improve gut health and nutrient uptake, based on the improved villus height of the small intestine compared to some sources of intact protein like SDP [52]. The beneficial effects of PDP on growth performance could be due to its content of short-chain peptides that are more easily absorbed by pigs than intact proteins [53] or even free amino acids [54].

It has been reported that PDP might improve gut health and nutrient uptake based on the improved villus height of the small intestine of animals that were fed this hydrolysate compared to animals that were fed a source of intact protein like SDP [52] or fish meal [11]. This is the first study performed using gene expression to determine the effects of PDP on intestinal function.

The outcome of the PCA individual factor map of the gene expression shows that the factorial scores of the SDP-PDP group tended to be closer to each other and more separate from the CON and SDP group scores in the jejunum and ileum. In addition, the correspondence of most of the arrows representing the significant genes in the PCA variables map and most of the samples in the SDP-PDP group in a similar position in both tissues indicates that there is a relationship between the higher expression levels in these genes and the differences that the SDP-PDP group showed from the CON and SDP groups. Heatmap representation also helped to visualize a partial clustering of the samples from the SDP-PDP treatment in the jejunum and ileum. In line with this, the statistical ANOVA showed a stronger effect of the SDP-PDP diet than SDP with respect to the CON diet. Considering the similarities between the results of the two tissues, although the statistical differences in gene expression found in the ileum according to the ANOVA $(P<0.05)$ did not occur in the FDR $(Q>0.2)$, we believe it was necessary to discuss these results. The lack of significance found in the FDR test in the ileum is probably due to the low number of samples that were amplified compared to the jejunum. The combination of inferential treatment comparison techniques (ANOVA and Tukey, essentially) and powerful exploratory methods (PCA and heatmap) provides a clearer and dual (individuals and genes) idea of the differences in gene expression. 
Proteins coded by these genes participate in the barrier function of gut cells, in nutrient transport in the mucosa, in digestion, in the immune response and in the metabolization of oxidation products.

The results from the barrier function showed that the expression of TFF3 and CLDN15 in the jejunum and MUC2, MUC13 and OCLN in the ileum was upregulated in the SDPPDP group compared to the CON group.

Changes in the jejunum indicate a potentiation by SDPPDP of the epithelial structure because the TFF3 gene participates in epithelial restitution and maintenance of intestinal mucosa integrity [25]. However, the CLDN15 gene codes for a pore-forming protein [23], which is important for the normal-sized morphogenesis of the small intestine [26]. In the ileum, the barrier promoting effect of the combination of SDP and PDP is also found at the epithelial integrity level, modulating the gene expression of OCLN, a tight junction involved in this process [55]. However, this functional diet also acts at different levels, and in this case, the SDP-PDP diet strengthens the protective mucus layer by upregulating the expression of the oligomeric mucus gel-forming genes, here represented by MUC2 and MUC13. Therefore, this effect represents an enhancement of the first barrier against invading bacteria, safeguarding the intestine and its structural integrity [56]. This barrier positive effect is in line with a study carried out by Smith et al. [22], in which animals infected with Lawsonia intracelullaris had impaired ileum gene expression of TFF3, CLDN15 and MUC2. In addition, Zhou et al. [30] also found that infection with different strains of enterotoxigenic E. coli F4 caused MUC13 downregulation in IPEC-J2 cells. Liu et al. [21] performed a study in which pigs that were infected with $E$. coli showed that supplementation with Capsicum oleoresin upregulated the expression level of genes related to the integrity of membranes in the ileal mucosa at d5 post infection, including the OCLN and MUC2 genes. Overall, the SDP-PDP diet could be a potential intervention for counteracting some problems that occur in this particular period of life.

As a consequence, diets also had a clear effect on the expression of genes related to the immune response and metabolization of oxidation products. Again, the SDP-PDP diet showed more changes than the SDP diet alone. Expression of immune response genes TLR4, IFNGR1 and GBP1 was increased in the SDP-PDP group; TLR4 compared to the CON and SDP groups in the jejunum; IFNGR1 compared to the CON group in the jejunum; and GBP1 compared to the SDP group in the jejunum and ileum.

TLR4 is a receptor involved in the recognition of lipopolysaccharide, a major cell wall component of Gram-negative bacteria [20], and IFNGR1 is part of the receptor that mediates the biological effects of IFN- $\mathrm{Y}$ [57]. The TLR4 and IFNGR1 genes have been reported to be upregulated in animals under stress and infection conditions in order to activate the innate immune response and fight against pathogens properly $[21,29,58]$. Thus, upregulation of TLR4 and IFNGR1 might suggest that piglets fed with SDP-PDP seem to be more prepared for controlling infective processes and other intestinal challenges that can occur during the weaning period. In addition, GBP1 is a GTPase that regulates the inhibition of proliferation and invasion of endothelial cells. It protects against epithelial apoptosis induced by inflammatory cytokines and subsequent loss of the barrier function [28]. Upregulation of GBP1 by the SDP-PDP diet is probably 
related to IFNGR1 upregulation because GBP1 expression is strongly induced by IFN-ץ [28], although an upregulation of IFN- $y$ was not observed in this study.

Focusing on nutrient transport, only the expression of the SLC11A2/DMT1 gene was significantly upregulated in animals fed with the SDP-PDP combination compared to the CON group in the jejunum. The divalent metal transporter ( $S C L 11 A 2 / D M T 1$ ) is located on the apical surface of the enterocyte and is involved in the intestinal Fe uptake [19]. SLC11A2/DMT1 gene expression is upregulated in circumstances of low Fe intake [27] and hyperglycemia conditions [59]. We have no evidence of differences in the Fe content or glycemic levels among experimental diets; therefore, the reason why the SDP-PDP treatment increased the expression of SLC11A2/DMT1 should be researched further.

Enzymes and hormones were also differentially expressed due to the SDP-PDP functional diet. On the one hand, the enzyme-coding genes $H N M T$ and $A P N$ were upregulated in the jejunum. Kröger et al. [32] reported that high dietary inclusion of fermentable CP increased the HNMT expression in the colon, which is a histamine-degrading enzyme. They determined that the histamine catabolism activity of HNMT counter-regulated the increased production of this biogenic amine, reducing the fecal score of the piglets fed with a high fermentable CP diet. Considering that all diets had an elevated CP level, an increase in this enzyme could show that SDP-PDP was attenuating the inflammatory effects of histamine more efficiently than other groups. On the other hand, APN is a Zn-dependent enzyme that takes part in the final digestion of peptides [60]. Its upregulation in the small intestine has been documented with products considered beneficial for intestinal health, such as the probiotic Lactococcus lactis [61]. Therefore, its increase due to the SDP-PDP diet may also be considered a positive physiological change. In the ileum, the GCG glucagon-encoding gene was more expressed in the SDP-PDP group than in the other groups. It is the precursor of the glucagon-like peptide GLP-2. As GLP-2 stimulates intestinal epithelial proliferation [62], its increased expression may be involved in the nutrient absorption surface. Accordingly, in this study the growth performance was higher for pigs fed PDP or SDP-PDP compared to CON. This is also in agreement with previous studies [52] in which PDP was associated with improvements in intestinal mucosa development measured by histometric indices.

Regarding the antioxidant defense mechanisms, we observed here that the expression of the SOD2 gene was also increased in the SDP-PDP group compared to both the SDP and CON groups. This mitochondrial enzyme is considered the first defense against reactive oxygen species (ROS) formed during normal cell metabolism [31]. Elimination of ROS by SOD2 can be considered as an antiinflammatory effect due to the important role that ROS plays in triggering and promoting inflammation [63]. As well as the TLR4 gene, expression of $S O D 2$ is stimulated by lipopolysaccharides but cytokines or ROS can also upregulate it [64]. Thus, changes in SOD2 gene expression can be derived from the TLR4 upregulation also induced by the SDP-PDP intervention.

The underlying mechanisms that produced these effects are still unknown; however, ingredients generated from the hydrolysis of animal proteins include free amino acids, small and large peptides and they might also contain bioactive peptides with biological functions beyond their nutritional value that 
could cause these effects. Numerous bioactive substances have been studied, but increasing interest is currently focused on bioactive peptides of animal origin. For instance, enzymatic hydrolysis of milk, egg or animal red blood cell fractions produces bioactive peptides with antioxidative, antimicrobial, antihypertensive and immunomodulatory functions, among others $[5,12,65-68]$. The possibility that PDP contains bioactive peptides that modify the gene expression of the intestine and influence intestinal health deserves to be explored.

\section{Conclusions}

The present study suggests that PDP can substitute or complement SDP in post-weaning diets because it showed the same capacity to increase growth performance in a soy-based diet in high-CP challenged piglets. In addition, the SDP-PDP diet demonstrated it could immunostimulate piglets without affecting growth performance, upregulating beneficial genes for the gut barrier function, the nutrient transport and immune response. These results give rise to research the underlying mechanisms beyond the PDP potential to improve intestinal function, which could be related to bioactive peptides due to its nature of protein hydrolysate.

\section{Abbreviations}

ADFI

Average daily feed intake

ADG

Average daily gain

BW

Body weight

CP

Crude protein

CON

Control

Crt

Cycle relative treshold

FDR

Benjamini-Hochberg false discovery rate

G

F:Feed efficiency

NE

Net energy

PCA

Principal component analysis

PDP

Porcine digestible peptides 
ROS

Reactive oxygen species

$\mathrm{RQ}$

Relative quantification

SDP

Spray dried plasma

SDP-PDP

Diet containing 1\% Spray-dried plasma and 2\% Porcine digestible peptides SBM

Soybean meal

\section{Declarations}

\section{Ethics approval}

The experimental procedures used in the two trials were approved by the Ethical Committee on Animal Experimentation of the Autonomous University of Barcelona (CEAAH 3817), and are in full compliance with national legislation following the EU-Directive 2010/63/EU for the protection of animals used for scientific purposes.

\section{Consent for publication}

Not applicable.

\section{Availability of data and material}

The datasets used and/or analysed during the current study are available from the corresponding author on reasonable request.

\section{Competing interests}

This research was partially funded by Bioiberica S.A.U and EB is employed by this company. The rest of the authors declare that they have no competing interests.

\section{Funding}

This project (AGL2016-75463-R) was supported by the Spanish Ministry of Economy, Industry and Competitivity (MINECO) and a FPU grant (Formación de Profesorado Universitario; FPU18/00401) from the Spanish Ministry of Science, Innovation and Universities (MICIU) to the first author. Financial support for this work was also provided by Bioiberica S.A.U. (Palafolls, Spain). 


\section{Authors contributions}

JFP, DSO and EB contributed to the conceptualization. JFP and DSO designed the study and developed the nutritional strategy provided in this study; CV and WG conducted the experiment at the farm and collected the performance data and intestine samples; FGS, LC and JMF conducted the gene expression analysis; MF contributed to statistical analysis; FJP was a major contibutor in writing the manuscript. FGS wrote the paper. JGP, EB and DSO supervised and guided the writing process of the paper. All authors read and approved the final manuscript.

\section{Acknowledgements}

The authors thank the ownership of the commercial farm for housing animals and providing production records.

\section{Authors' information (optional)}

Not applicable.

\section{References}

1. Lallès J-P, Bosi P, Smidt H, Stokes CR. Weaning - A challenge to gut physiologists. Livest Sci. 2007;108(1-3):82-93.

2. Domeneghini C, Di Giancamillo A, Arrighi S, Bosi G. Gut-trophic feed additives and their effects upon the gut structure and intestinal metabolism. State of the art in the pig, and perspectives towards humans. Histol Histopathol. 2006;21(3):273-83.

3. Gresse R, Chaucheyras-Durand F, Fleury MA, Van de Wiele T, Forano E, Blanquet-Diot S. Gut microbiota dysbiosis in postweaning piglets: Understanding the keys to health. Vol. 25, Trends Microbiol. 2017;25(10):851-73.

4. Pluske JR, Le Dividich J, Verstegen MWA. Weaning the pig: concepts and consequences. Wageningen: Wageningen Academic Publishers; 2003.

5. Bhat ZF, Kumar S, Bhat HF. Bioactive peptides of animal origin: a review. J Food Sci Technol. 2015;52(9):5377-92.

6. Bosi P, Casini L, Finamore A, Cremokolini C, Merialdi G, Trevisi P, et al. Spray-dried plasma improves growth performance and reduces inflammatory status of weaned pigs challenged with enterotoxigenic Escherichia coli K88. J Anim Sci. 2004;82:1764-72.

7. Pérez-Bosque A, Amat C, Polo J, Campbell JM, Crenshaw J, Russell L, et al. Spray-dried animal plasma prevents the effects of Staphylococcus aureus enterotoxin B on intestinal barrier function in weaned rats. J Nutr. 2018;136(11):2838-43. 
8. Pérez-Bosque A, Miró L, Polo J, Russell L, Campbell J, Weaver E, et al. dietary plasma proteins modulate the immune response of diffuse gut-associated lymphoid tissue in rats challenged with Staphylococcus aureus enterotoxin B. J Nutr. 2018;138(3):533-7.

9. Figueroa J, Solà-Oriol D, Guzmán-Pino SA, Chetrit C, Borda E, Pérez JF. The use of porcine digestible peptides and their continuity effect in nursery pigs. J Anim Sci. 2016;94(4):1531-40.

10. Solà-Oriol D, Roura E, Torrallardona D. Feed preference in pigs: Effect of selected protein, fat, and fiber sources at different inclusion rates. J Anim Sci. 2011;89(10):3219-27.

11. Xin G, QiuGang M, Cheng J, ShaoChen G, Keller G. Evaluation of DPS supplement in early-weaned pig diets. Acta Zoonutrimenta Sin. 2001;13(2):15-9.

12. Hou Y, Wu Z, Dai Z, Wang G, Wu G. Protein hydrolysates in animal nutrition: Industrial production, bioactive peptides, and functional significance. J Anim Sci Biotechnol. 2017;8(1):1-13.

13. FEDNA. Necesidades nutricionales para ganado porcino. $2^{\text {nd }}$ ed. Madrid: Fedna; 2013.

14. National Research Council. Nutrient Requirements of Swine. $11^{\text {th }}$ rev ed. Washington:Natl Acad Press; 2012.

15. AOAC. Official methods of analysis of the AOAC. 15th ed. Washington: Association of official analytical chemists; 1990.

16. AOAC International. Official methods of analysis of AOAC International. 18th ed. Gaithersburg: Official methods of analysis of AOAC International; 2007.

17. AOAC International. Official methods of analysis of AOAC International. 18th ed. Washington: Official methods of analysis of AOAC International; 2005.

18. Van Soest PJ, Robertson JB, Lewis BA. Methods for Dietary Fiber, Neutral Detergent Fiber, and Nonstarch Polysaccharides in Relation to Animal Nutrition. J Dairy Sci. 1991;74(10):3583-97.

19. Garrick MD, Dolan KG, Horbinski C, Ghio AJ, Higgins D, Porubcin M, et al. DMT1: A mammalian transporter for multiple metals. BioMetals. 2003;16(1):41-54.

20. Takeda K, Kaisho T, Akira S. Toll-like receptors. Annu Rev Immunol. 2003;21(1):335-76.

21. Liu Y, Song M, Che TM, Lee JJ, Bravo D, Maddox CW, et al. Dietary plant extracts modulate gene expression profiles in ileal mucosa of weaned pigs after an Escherichia coli infection. J Anim Sci. 2014;92(5):2050-62.

22. Smith SH, Wilson AD, Van Ettinger I, Macintyre N, Archibald AL, Ait-Ali T. Down-regulation of mechanisms involved in cell transport and maintenance of mucosal integrity in pigs infected with Lawsonia intracellularis. Vet Res. 2014;45(1):55.

23. Khan N, Asif AR. Transcriptional regulators of claudins in epithelial tight junctions. Mediators Inflamm. 2015;2015(1).

24. Xu S, Wang D, Zhang P, Lin Y, Fang Z, Che L, et al. Oral administration of Lactococcus lactisexpressed recombinant porcine epidermal growth factor stimulates the development and promotes the health of small intestines in early-weaned piglets. J Appl Microbiol. 2015;119(1):225-35. 
25. Taupin D, Podolsky DK. Trefoil factors: initiators of mucosal healing. Nat Rev Mol Cell Biol. 2003;4(9):721-32.

26. Tamura A, Kitano Y, Hata M, Katsuno T, Moriwaki K, Sasaki H, et al. Megaintestine in claudin-15deficient mice. Gastroenterology. 2008;134(2).

27. Hansen SL, Trakooljul N, Liu H-C, Moeser AJ, Spears JW. Iron transporters are differentially regulated by dietary iron, and modifications are associated with changes in manganese metabolism in young pigs.J Nutr. 2009;139(8):1474-9.

28. Schnoor M, Betanzos A, Weber DA, Parkos CA. Guanylate-binding protein-1 is expressed at tight junctions of intestinal epithelial cells in response to interferon- $\gamma$ and regulates barrier function through effects on apoptosis. Mucosal Immunol. 2009;2(1):33-42.

29. Badia R, Lizardo R, Martinez P, Badiola I, Brufau J. The influence of dietary locust bean gum and live yeast on some digestive immunological parameters of piglets experimentally challenged with Escherichia coli. J Anim Sci. 2012;90 Suppl 4:260-2.

30. Zhou C, Liu Z, Jiang J, Yu Y, Zhang Q. Differential gene expression profiling of porcine epithelial cells infected with three enterotoxigenic Escherichia coli strains. BMC Genomics. 2012;13(1):330.

31. Chmielewska M, Łosiewicz K, Podlasz P, Wąsowicz K. The expression of mitochondrial, cytoplasmic and extracellular superoxide dismutase in the colonic wall of pigs suffering from swine dysenteria. Pol J Vet Sci. 2013;16(3):463-7.

32. Kröger S, Pieper R, Schwelberger HG, Wang J, Villodre Tudela C, Aschenbach JR, et al. Diets high in heat-treated soybean meal reduce the histamine-induced epithelial response in the colon of weaned piglets and increase epithelial catabolism of histamine. PLoS One. 2013;8(11):e80612.

33. R Development Core Team. R: a language and environment for statistical computing. R Foundation for Statistical Computing, Vienna, Austria; 2013.

34. Gentleman RC, Carey VJ, Bates DM, Bolstad B, Dettling M, Dudoit S, et al. Bioconductor: open software development for computational biology and bioinformatics. Genome Biol. 2004;5(10).

35. Benjamini Y, Hochberg Y. Controlling the false discovery rate.J. R. Stat. Soc. B. 1995;57(1):289-300

36. Tukey JW. Comparing individual means in the analysis of variance. Biometrics. 1949;5(2):99.

37. Lê S, Josse J, Husson F. FactoMineR: An R package for multivariate analysis. J Stat Softw. 2008;25(1):1-18.

38. Murtagh F, Legendre P. Ward's hierarchical agglomerative clustering method: Which algorithms implement Ward's criterion? J Classif. 2014;31(3):274-95.

39. Everitt B. Cluster analysis. London: Heinemann Educ. Book. 1974.

40. Warnes G, Bolker B, Bonebakker L, Gentleman R, Liaw W, Lumley T, et al. gplots: Various R programming tools for plotting data. $\mathrm{R}$ package version 3.0.1.1. 2015.

41. Carbonaro M, Maselli P, Nucara A. Relationship between digestibility and secondary structure of raw and thermally treated legume proteins: A Fourier transform infrared (FT-IR) spectroscopic study. Amino Acids. 2012;43(2):911-21. 
42. Pieper R, Villodre Tudela C, Taciak M, Bindelle J, Pérez JF, Zentek J. Health relevance of intestinal protein fermentation in young pigs. Anim. Heal. Res. Rev. Cambridge University Press; 2016;17(2):137-47.

43. Li DF, Nelssen JL, Reddy PG, Blecha F, Klemm RD, Giesting DW, et al. Measuring suitability of soybean products for early-weaned pigs with immunological criteria. J Anim Sci. 1991;69(8):3299307.

44. Salgado P, Freire JPB, Mourato M, Cabral F, Toullec R, Lallès JP. Comparative effects of different legume protein sources in weaned piglets: Nutrient digestibility, intestinal morphology and digestive enzymes. Livest Prod Sci. 2002;74(2):191-202.

45. Prohászka L, Baron F. The predisposing role of high dietary protein supplies in enteropathogenic $\mathrm{E}$. coli infections of weaned pigs. bl. Vet. Med. B.1980;27(3):222-32.

46. Solà-Oriol D, Figueroa J, Borda E, Chetrit C, Pérez JF.The effect of different animal and vegetable protein sources on the feed intake and weight gain of piglets. Anim. Sci. 2010;88 E-Suppl. 2:92.

47. Martínez-Puig, D, Anguita M, BaucellsF, Borda E, Pérez JF, Chetrit C. Evidence of a preference in piglets for an animal protein hydrolysate. In: Proceedings of the Joint Annual Meeting ADSA-PSAAMPA-ASAS. 2007 July 8-12; San Antonio, Tx, USA. J Anim Sci. 2007;85 Suppl 1:310.

48. Torrallardona D. Spray dried animal plasma as an alternative to antibiotics in weanling pigs. AsianAustralasian J. Anim. Sci. 2010;23(1):131-48.

49. Ermer PM, Miller PS, Lewis AJ. Diet preference and meal patterns of weanling pigs offered diets containing either spray-dried porcine plasma or dried skim milk. J Anim Sci. 1994;72(6):1548-54.

50. Pérez-Bosque A, Miró L, Amat C, Polo J, Moretó M. The anti-inflammatory effect of spray-dried plasma is mediated by a reduction in mucosal lymphocyte activation and infiltration in a mouse model of intestinal inflammation. Nutrients. 2016;8(10).

51. Myers AJ, Goodband RD, Tokach MD, Dritz SS, DeRouchey JM, Nelssen JL. The effects of porcine intestinal mucosa protein sources on nursery pig growth performance. J Anim Sci. 2014;92(2):78392.

52. Borda, E, Martínez-Puig D, Pérez JF. An hydrolyzed protein concentrate (Palbio 62) increases feed intake and villus height in early weaning pigs. In: Van der Honing Y. Book Of Abstracts Of The 56th Annual Meeting Of The EAAP. 2005 June 5-8. Uppsala, SW. Wageningen: Wageningen Academ. Publ. 2005;2:154.

53. Gilbert ER, Wong EA, Webb KE. Board-invited review: Peptide absorption and utilization: Implications for animal nutrition and health. J Anim Sci. 2008;86(9):2135-55.

54. Rérat A, Nunes CS, Mendy F, Roger L. Amino acid absorption and production of pancreatic hormones in non-anaesthetized pigs after duodenal infusions of a milk enzymic hydrolysate or of free amino acids. Br J Nutr. 1988;60(1):121-36.

55. McCarthy KM, Skare IB, Stankewich MC, Furuse M, Tsukita S, Rogers RA, et al. Occludin is a functional component of the tight junction. J Cell Sci. 1996;109(9):2287-98. 
56. Hansson GC. Role of mucus layers in gut infection and inflammation.Curr Opin Microbiol. 2012; 15(1):57-62.

57. Xing F, Jiang $C$, Liang $S$, Kang $L$, Jiang $Y$. Genomic structure and characterization of mRNA expression pattern of porcine interferon gamma receptor 1 gene. Int $\mathrm{J}$ Immunogenet. 2010;37(6):477-85.

58. Vaure C, Liu Y. A comparative review of toll-like receptor 4 expression and functionality in different animal species. Front Immunol. 2014;5:1-15.

59. Zhao L, Bartnikas T, Chu X, Klein J, Yun C, Srinivasan S, et al. Hyperglycemia promotes microvillus membrane expression of DMT1 in intestinal epithelial cells in a PKCa-dependent manner. FASEB J. 2019;33(3):3549-61.

60. Bank U, Bohr URM, Reinhold D, Lendeckel U, Ansorge S, Malfertheiner P, et al. Inflammatory bowel diseases: Multiple benefits from therapy with dipepridyl- and alanyl-aminopeptidase inhibitors. Front. Biosci. 2008;6(13-14):3699-713.

61. Xu S, Wang D, Zhang P, Lin Y, Fang Z, Che L, et al. Oral administration of Lactococcus lactis expressed recombinant porcine epidermal growth factor stimulates the development and promotes the health of small intestines in early-weaned piglets. J Appl Microbiol. 2015;119(1):225-35.

62. Jasleen J, Ashley SW, Shimoda N, Zinner MJ, Whang EE. Glucagon-like peptide 2 stimulates intestinal epithelial proliferation in vitro. Dig Dis Sci. 2002;47(5):1135-40.

63. Li C, Zhou HM. The role of manganese superoxide dismutase in inflammation defense. Enzyme Res. 2011;2011:387176.

64. Visner GA, Dougall WC, Wilson JM, Burr IA, Nick HS. Regulation of manganese superoxide dismutase by lipopolysaccharide, interleukin-1, and tumor necrosis factor. Role in the acute inflammatory response. J Biol Chem. 1990;265(5):2856-64.

65. Haque E, Chand R, Kapila S. Biofunctional properties of bioactive peptides of milk origin. Food Rev Int. 2009;25(1):28-43.

66. Sánchez A, Vázquez A. Bioactive peptides: A review. Food Qual Saf. 2017;1:29-46.

67. Dieterich F. Development and characterization of protein hydrolysates originated from animal agro industrial byproducts. J Dairy Vet Anim Res. 2014;1(2):00012.

68. Bah CSF, Carne A, McConnell MA, Mros S, Bekhit AEDA. Production of bioactive peptide hydrolysates from deer, sheep, pig and cattle red blood cell fractions using plant and fungal protease preparations. Food Chem. 2016;202:458-66.

\section{Figures}




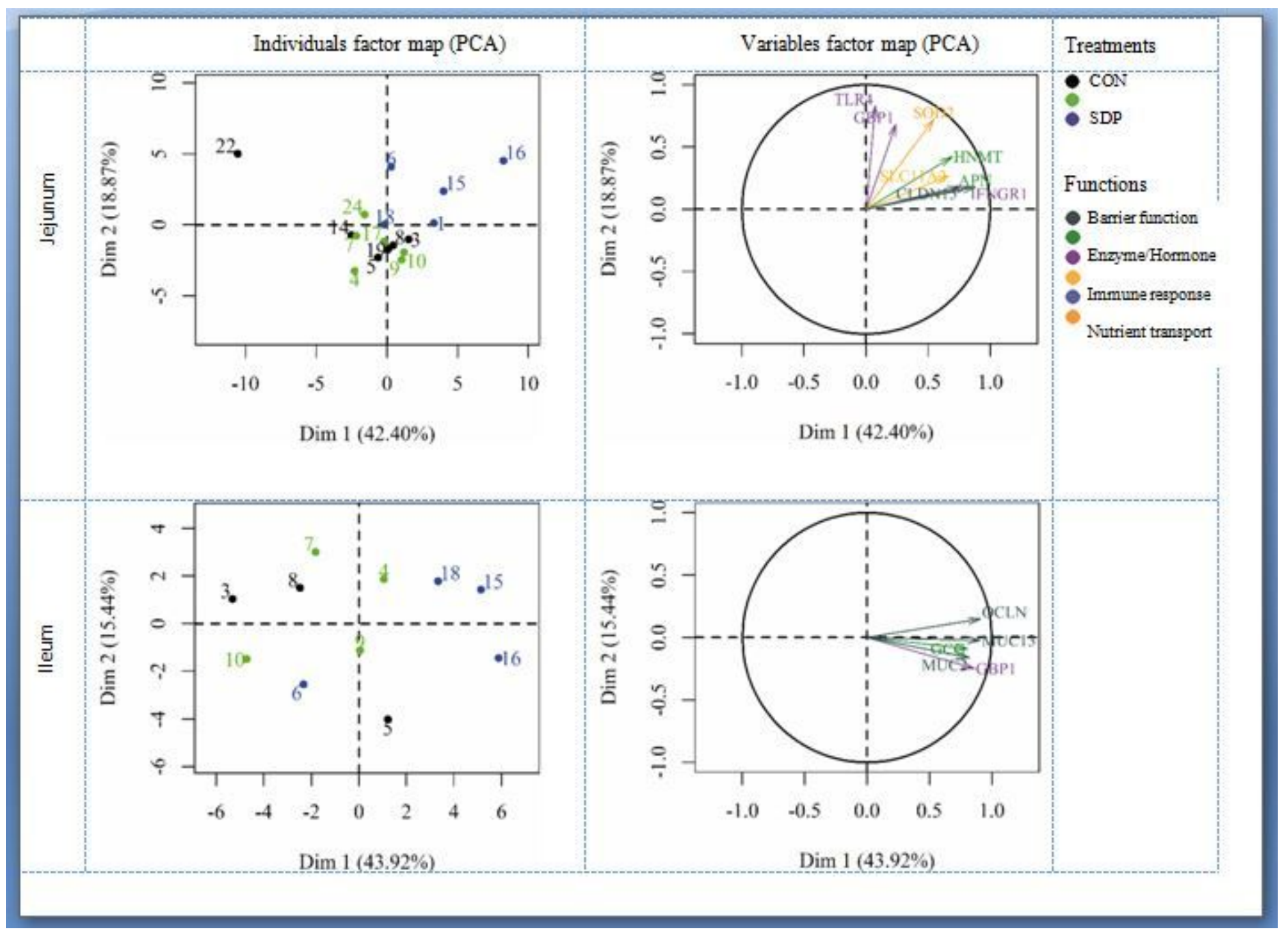

Figure 1

Principal component analysis (PCA).

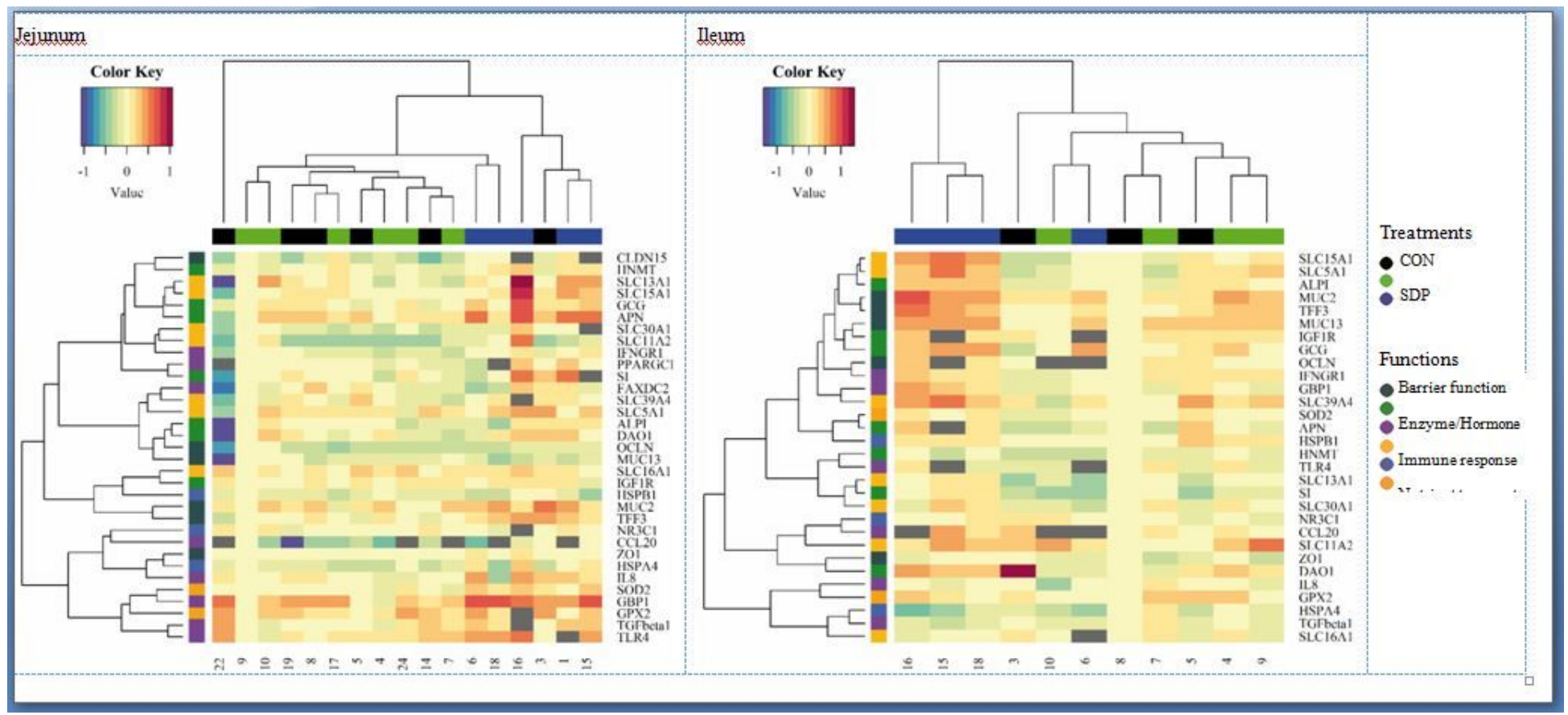


Figure 2

Heatmap representing the gene expression of each sample in each gene on trial 2.

\section{Supplementary Files}

This is a list of supplementary files associated with this preprint. Click to download.

- Additionalfile.xlsx

- CoverletterF.Gonzalez.pdf 